\title{
Recovery from severe metabolic alkalosis with acute kidney injury due to gastric cancer: a case report
}

\author{
Kenta Hirai ${ }^{1}$, Kei Nagai ${ }^{1}$, Takashi Ono ${ }^{1}$, Masayuki Nakajima ${ }^{1}$, Tomohiro Hayakawa ${ }^{1}$, \\ Yoshinori Sakata ${ }^{1}$, and Yoshiharu Nakamura ${ }^{1}$
}

${ }^{1}$ Kamisu Saiseikai Hospital, Japan

\begin{abstract}
Objective: Most cases of severe metabolic alkalosis have many causes that may result in renal failure and death. Therefore, these should be treated promptly for successful recovery.

Patient: A 61-year-old man was hospitalized due to an acute kidney injury (creatinine level of $4.36 \mathrm{mg} / \mathrm{dL}$ ) after a 3-month history of anorexia and recurrent vomiting. He had been treated for tuberculosis in the past.

Results: Blood gas analysis revealed severe metabolic alkalosis with $\mathrm{pH}=7.66, \mathrm{HCO}_{3}=94 \mathrm{mmol} / \mathrm{L}$, and $\mathrm{pCO}_{2}=82.0 \mathrm{mmHg}$. Routine biochemical examination revealed severe hypokalemia $(\mathrm{K} 2.9 \mathrm{mEq} / \mathrm{L})$ that was associated with prolonged QTc interval $(0.52$ seconds) on the electrocardiogram. Gastrofiberscopic examination also revealed severe stenosis and ulcerated scarring of the gastric pylorus and severe esophagitis. Intravenous hydration and correction of hypokalemia improved renal function and resolved metabolic alkalosis. An investigation that was repeated after 6 days revealed a creatinine level of $1.58 \mathrm{mg} / \mathrm{dL}, \mathrm{pH}=7.47, \mathrm{HCO}=23.4$ $\mathrm{mmol} / \mathrm{L}, \mathrm{K}=3.6 \mathrm{mEq} / \mathrm{L}$, and QTc of 0.45 seconds. The patient underwent gastrectomy and adenocarcinoma was observed.

Conclusion: We described a resolved case of severe metabolic alkalosis and acute kidney injury in a rural medical setting following conservative management.
\end{abstract}

Key words: acute kidney disease, metabolic alkalosis, gastric cancer

\section{Introduction}

Metabolic alkalosis is commonly observed in intensive care units and emergency rooms ${ }^{1)}$. However, severe metabolic alkalemia is rare and the mortality associated with it is $80 \%$ when the $\mathrm{pH}$ is $>7.65^{2}$. Major organ systems are affected, causing cardiac arrhythmias and neurological defects leading to fatal outcomes.

Gastric outlet obstruction (GOO) often induces metabolic alkalosis and its diagnosis is usually straightforward based on the history, radiological findings, and gastric endoscopy. Classical biochemical consequences of adult GOO are rarely observed in the modern era because the patients

Received: May 12, 2020

Accepted: July 18, 2020

Correspondence: Kei Nagai, Kamisu Saiseikai Hospital, 7-2-45 Shitte-Chuo, Kamisu, Ibaraki 314-0112, Japan

E-mail:knagai@md.tsukuba.ac.jp

This is an open-access article distributed under the terms of the Creative Commons Attribution Non-Commercial No Derivatives
(by-nc-nd) License $<\mathrm{http} / / /$ creativecommons.org/ licenses/by-nc-nd/4.0/>. are identified and treated to prevent dehydration and metabolic acid-base disturbances in hospitals having good access to medical care.

However, in the rural medical settings, the patients tend to live in remote locations and chronically progressive neurogenic and gastrointestinal signs are often overlooked. In this case report, gastric resection along with conventional treatment was considered to reverse the metabolic alkalosis and renal injury thereby enabling to conduct invasive procedures and contrast-enhanced imaging examinations.

\section{Patient and clinical course}

A 61-year-old man was hospitalized due to an acute kidney injury (creatinine level of $4.36 \mathrm{mg} / \mathrm{dL}$ ) following a 3 -month history of anorexia and recurrent vomiting. In the past he had been successfully treated for tuberculosis with appropriate antibiotics. The patient was a heavy drinker, ingesting $100 \mathrm{~g}$ ethanol/day. The patient provided consent for the publication of this case report. 


\section{Results}

The level of consciousness of the patient was I-1 on the Japan Coma Scale. Blood gas analysis revealed severe metabolic alkalosis with $\mathrm{pH}$ of $7.66, \mathrm{HCO}_{3}=94 \mathrm{mmol} / \mathrm{L}$, and $\mathrm{pCO}_{2}=82.0 \mathrm{mmHg}$ (Table 1). Routine biochemical examination revealed moderate hypokalemia $(\mathrm{K} 2.9 \mathrm{mEq} / \mathrm{L})$ that was associated with prolonged QTc interval ( 0.52 seconds) on the electrocardiogram. Concurrent insufficiency of the serum electrolytes such as magnesium, calcium, and phosphorus was not observed (Table 1).

Computed tomography (CT) demonstrated gastric pyloric stenosis and gastrofiberscopic examination revealed severe stenosis and ulcerated scarring of the gastric pylorus. Esophagitis of the lower esophageal sphincter was observed (Figure 1). Pathological examination of the endoscopic biopsy specimen did not rule out malignant disease; therefore, surgical resection of the gastric pylorus was considered. However, renal injury of the patient made it difficult conduct further investigations using contrast-enhanced imaging and to perform surgery. Initial administration of saline $(3,500$ $\mathrm{mL} /$ day) and correction of hypokalemia $(80 \mathrm{mEq} /$ day $)$ steadily improved his serum biochemical parameters (Figure 2) thereby limiting the deterioration of his consciousness and alkalemia was treated using conventional infusion therapy without acid infusion or renal replacement therapy without mandatory ventilation. A high-dose proton pump inhibitor was administered intravenously to reduce the risk of losing gastric acid. Although there was a risk of fatal arrhythmia due to prolonged QT interval, cardiac events were not observed during the initial therapy.

An investigation that was repeated 6 days later revealed a serum creatinine level of $1.58 \mathrm{mg} / \mathrm{dL}, \mathrm{pH}=7.47, \mathrm{HCO}_{3}=23.4$ $\mathrm{mmol} / \mathrm{L}, \mathrm{K}$ level of $3.6 \mathrm{mEq} / \mathrm{L}$, and prolonged QTc of 0.45 seconds. A creatinine level of $1.08 \mathrm{mg} / \mathrm{dL}$ was observed 12 days after admission. He then underwent contrast-enhanced CT on day 14 of the admission (Figure 2). The consciousness level of the patient became completely clear and a central venous catheter was inserted to administer pre-operative nutritional conditioning.

After an adequate investigation, an open distal gastrectomy was performed on day 21 (Figure 3 ) and gastric adenocarcinoma was observed. Complications were not observed after the surgery, his renal function gradually improved, and the glomerular filtration rate was estimated to be about 90 $\mathrm{mL} / \mathrm{min} / 1.73 \mathrm{~m}^{2}$ on day 28 . He was discharged on day 38 after the admission.

After surgical treatment, he received enough liquid foods and obvious renal injury was not observed several months after the follow-up period as an outpatient and he received adjuvant chemotherapy.
Table 1 Laboratory findings

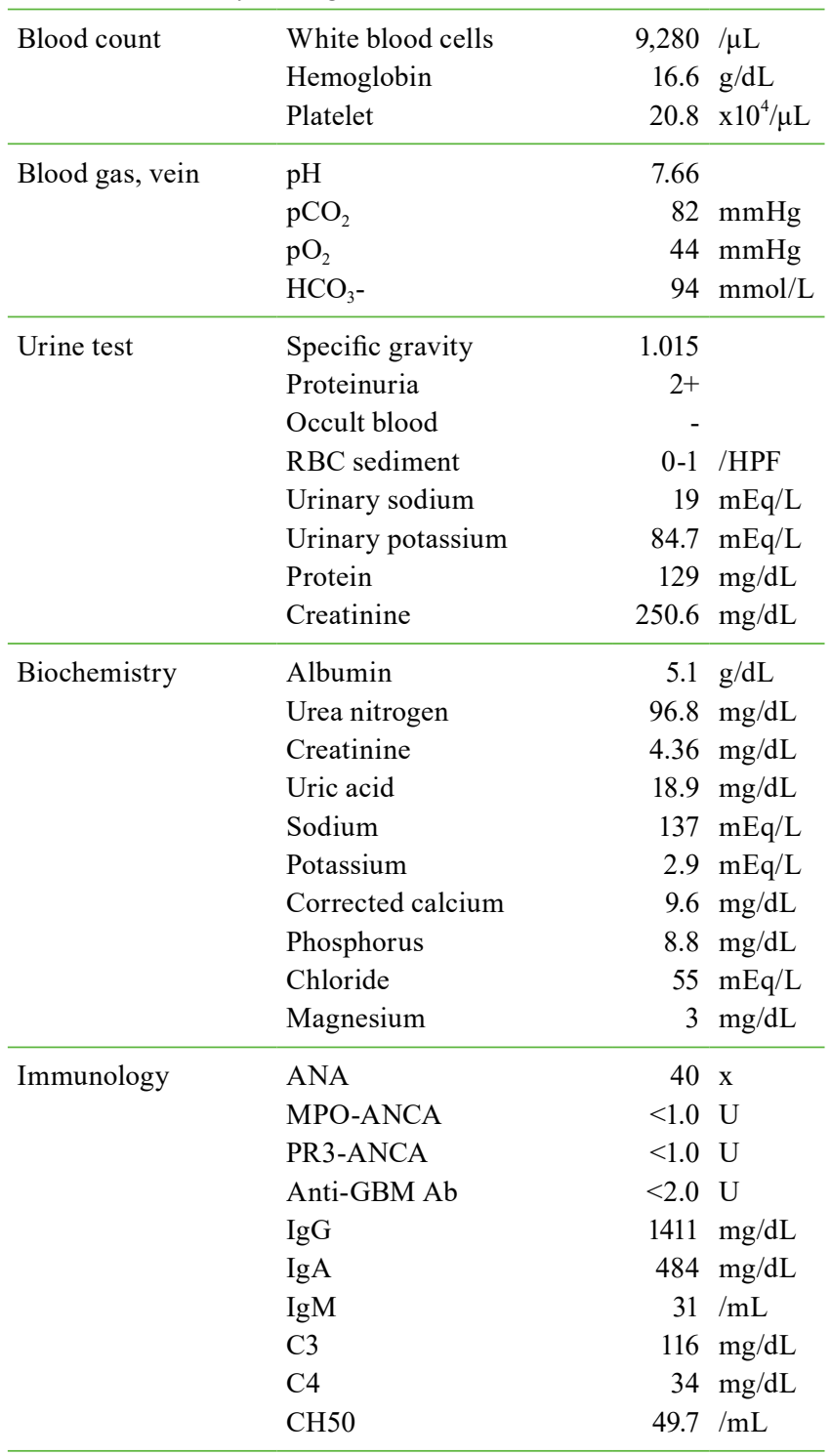

RBC: red blood cells; ANA: anti-nuclear acid antibody; MPO-ANCA: myeloperoxidase anti-neutrophil cytoplasmic antibody; PR3-ANCA: proteinase 3 anti-neutrophil cytoplasmic antibody; GBM: glomerular basement membrane; Ig: immunoglobulin; C: complement.

\section{Discussion}

Pyloric stenosis or GOO, the major cause of metabolic alkalosis is often treated using surgical or endoscopic procedures $^{3,4)}$. Although most published cases related to metabolic alkalosis and acute kidney injury were caused by pyloric ulcers, the incidence of peptic ulcer-related disease has decreased steadily worldwide ${ }^{5,6}$. Table 2 revealed few reports related to gastric cancer-induced GOO resulting in metabolic alkalosis and acute kidney injury ${ }^{7}$. The examination to indicate presence of gastric scirrhous carcinoma was considered in such cases. 


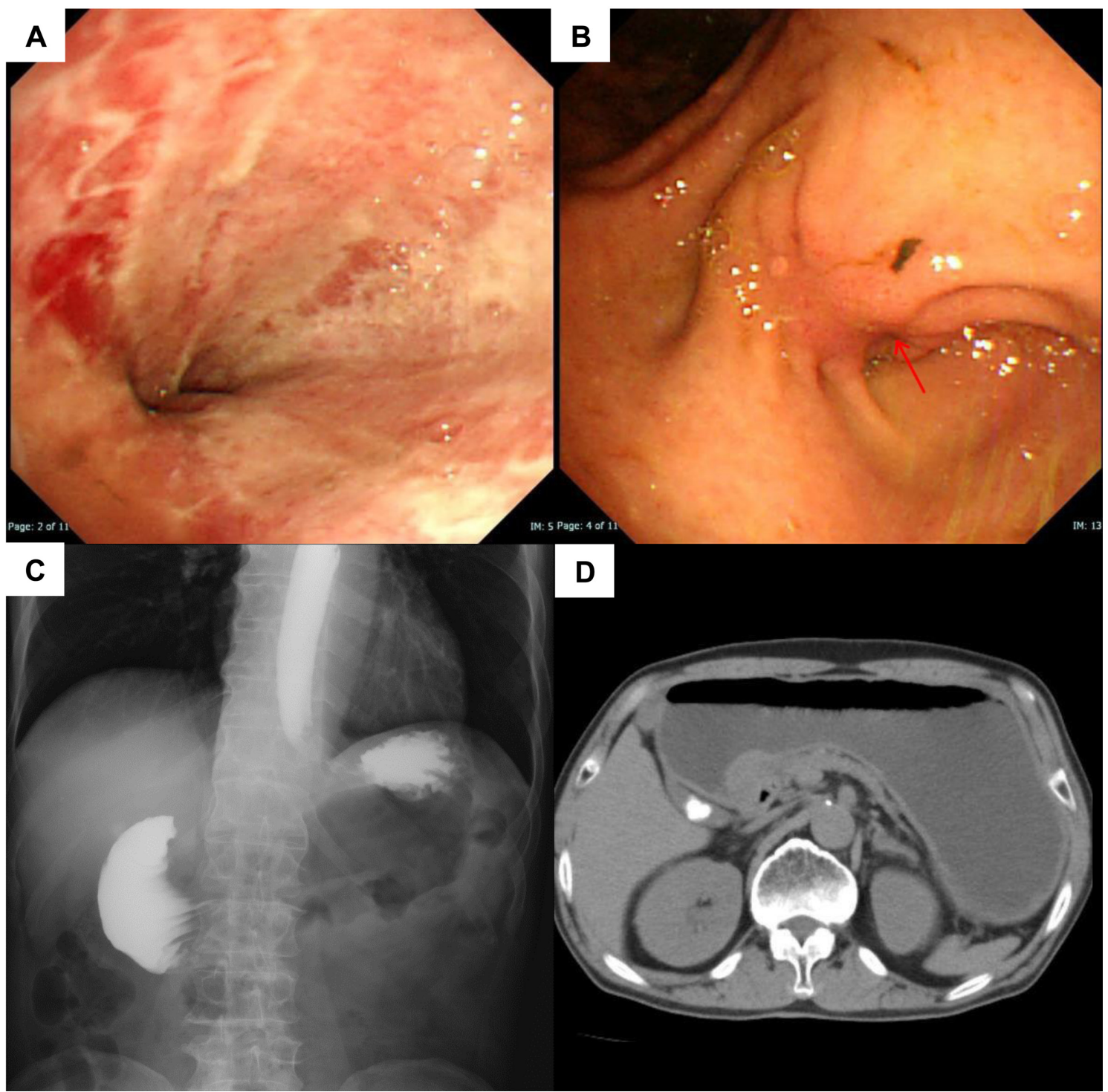

Figure 1 Endoscopic and radiological examinations reveal gastric outlet obstruction (GOO).

On the day of admission, gastrofiberscopic examination (A, B), enema examination (C), and computed tomography (D) demonstrated gastric pyloric stenosis along with severe stenosis and ulcerated scarring of gastric pylorus and esophagitis of the lower esophagus.

Although many cases of metabolic alkalosis have previously been reported, mortality rate is $80 \%$ because the $\mathrm{pH}$ >7.65. In the Table 2, it was observed that one patient recovered from severe renal dysfunction after he received conventional infusion therapy without dialysis or disease-specific acid infusion ${ }^{8)}$. This report presented the most severe case of metabolic alkalosis ever reported where GOO was complicated by an acute kidney injury. The rural setting of the hospital was partially responsible for the late diagnosis of GOO in the patient.

The multifactorial pathophysiology of kidney injury in GOO results in persistent vomiting leading to dehydration and ultimately pre-renal failure with the risk for acute tubu- lar necrosis. Additionally, loss of gastric fluid also results in hypokalemic and hypochloremic metabolic alkalosis. Therefore, it is essential to maintain fluid volume, electrolyte balance and to correct acid-base disturbances. Acidbase disturbances are quickly ameliorated when the kidneys are better-perfused ${ }^{9)}$ because a normal kidney has a high capacity for reabsorption of $\mathrm{HCO}_{3}{ }^{10}$. Various treatments for severe metabolic alkalosis are conventional and renal replacement therapies, mandatory ventilation, and disease specific acid infusion. The patient diagnosed with chlorideresponsive alkalosis was treated with (conventional) infusion therapy. Additionally, GOO is also treated conservatively by administering intravenous proton pump inhibitors 


\section{Journal of Rural Medicine}

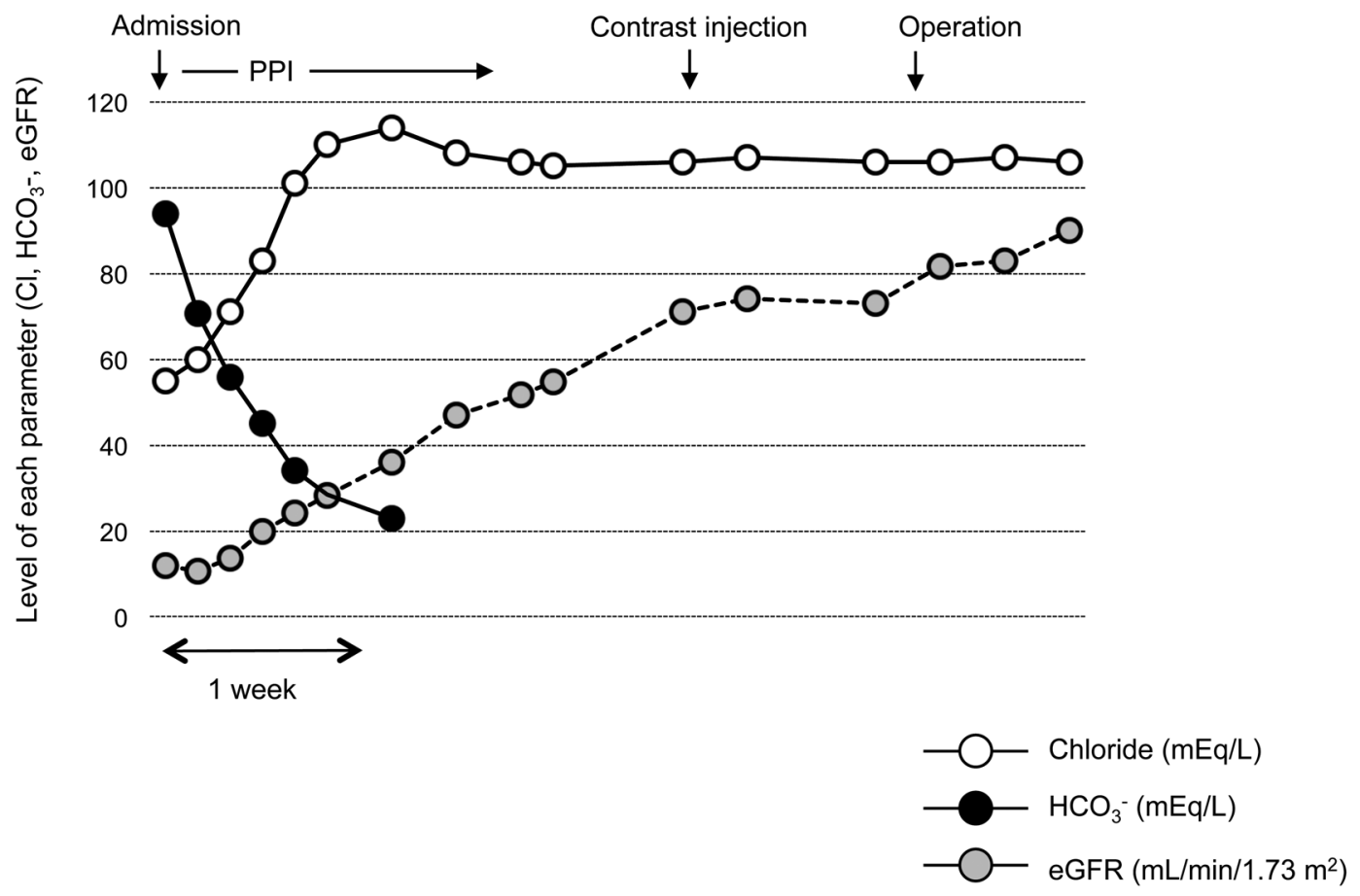

Figure 2 Clinical course.

Time course of the conservative surgical therapy, levels of blood chloride, $\mathrm{HCO}_{3}^{-}$, and estimated glomerular filtration rate (eGFR) are shown.

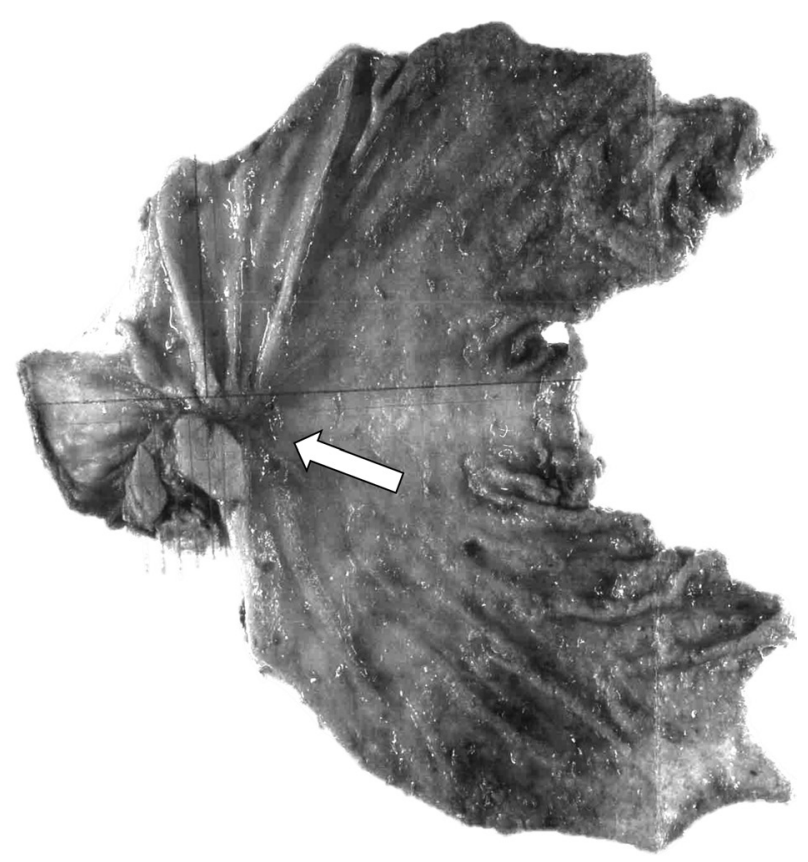

Figure 3 Macroscopic findings of this patient.

Surgical specimen of this case is presented. The arrow indicates the location of outlet obstruction that indicates an adenocarcinoma. until surgical treatment ${ }^{11)}$.

Once metabolic disturbances occur, urgent management with the help of intravenous resuscitation is required. Although several treatments are available for treating metabolic alkalosis, there is little evidence regarding the speed of recovery. The patient in this report recovered late and had normal kidney function 28 days after starting treatment.

\section{Conclusion}

In the rural medical setting, the renal injury and alkalosis are occasionally severe. Nevertheless, the effectiveness of the initial conventional treatment without renal replacement therapy could lead to successful diagnosis and treatment for the cause of metabolic alkalosis and gastric cancer. 
Table 2 Cases presenting with mechanical gastric outlet obstruction, metabolic alkalosis, and acute kidney injury

\begin{tabular}{|c|c|c|c|c|c|c|c|}
\hline Year & Patient & Cause & $\mathrm{pH}$ & Chloride & Kidney injury & Therapy & Outcome \\
\hline $1964^{3)}$ & 13 cases & Peptic Ulcer and Carcinoma & Various & Various & Urea various & Surgical + Various & Various \\
\hline $1971^{8)}$ & $48 \mathrm{M}$ & Peptic Ulcer & 7.44 & 61 & Urea $350 \mathrm{mg} / \mathrm{dL}$ & PD, Surgical & $\begin{array}{l}\text { Complete } \\
\text { Recovery }\end{array}$ \\
\hline $1997^{12)}$ & $67 \mathrm{~F}$ & Gall Stone & NA & (HCO3 43) & Cre 4.98 mg/dL & Infusion, Necropsy & Death \\
\hline $2006^{13)}$ & $54 \mathrm{M}$ & Peptic Ulcer & 7.49 & 78 & Cre $7.4 \mathrm{mg} / \mathrm{dL}$ & Infusion, Surgical & Recovery \\
\hline $2009^{14)}$ & $26 \mathrm{M}$ & Peptic Ulcer & 7.65 & 58 & Cre $7.74 \mathrm{mg} / \mathrm{dL}$ & Infusion, Surgical & Recovery \\
\hline $2014 *^{7)}$ & $51 \mathrm{M}$ & Adenocarcinoma & 7.6 & 76 & Cre $6.5 \mathrm{mg} / \mathrm{dL}$ & HD, Surgical & Recovery \\
\hline $2020^{\#}$ & $61 \mathrm{M}$ & Adenocarcinoma & 7.66 & 55 & Cre $4.36 \mathrm{mg} / \mathrm{dL}$ & $\begin{array}{c}\text { Infusion, Surgical and } \\
\text { chemotherapy }\end{array}$ & $\begin{array}{l}\text { Complete } \\
\text { Recovery }\end{array}$ \\
\hline
\end{tabular}

*Not available in PubMed search. "Present case. HD: hemodialysis; PD: peritoneal dialysis; ESKD: end-stage kidney disease.

\section{References}

1. Hodgkin JE, Soeprono FF, Chan DM. Incidence of metabolic alkalemia in hospitalized patients. Crit Care Med 1980; 8: 725-728. [Medline] [CrossRef]

2. Anderson LE, Henrich WL. Alkalemia-associated morbidity and mortality in medical and surgical patients. South Med J 1987; 80: 729-733. [Medline] [CrossRef]

3. Howe CT, Lequesne LP. Pyloric stenosis: the metabolic effects. Br J Surg 1964; 51: 923-932. [Medline] [CrossRef]

4. Palacios-García L, Gutiérrez-Macías A, García-González P, et al. Life-threatening hyponatremia, hypokalemia, and metabolic alkalosis after intragastric balloon placement. Gastrointest Endosc 2016; 83: 855-856. [Medline] [CrossRef]

5. Kaye P. Acquired pyloric stenosis resulting in hypokalaemic, hyperchloraemic normal anion gap metabolic acidosis. Persistent vomiting in an adult: cause and effect. BMJ Case Rep 2018; 2018: bcr-2017-222800. [Medline] [CrossRef]

6. Hall R, Royston C, Bardhan KD. The scars of time: the disappearance of peptic ulcer-related pyloric stenosis through the 20th century. J R Coll Physicians Edinb 2014; 44: 201-208. [Medline] [CrossRef]

7. Shikino K, Ikusaka M, Hayashi H, et al. Acute renal failure with metabolic alkalosis due to gastric scirrhous carcinoma. Gen Med (Los Angel) 2014; 15 : 136-139.

8. Beach FX, Jones ES. Metabolic alkalosis treated with intravenous hydrochloric acid. Postgrad Med J 1971; 47: 516-520. [Medline] [CrossRef]

9. Amundson DE, Diamant J. Severe metabolic alkalosis. South Med J 1994; 87: 275-277. [Medline] [CrossRef]

10. Galla JH. Metabolic alkalosis. J Am Soc Nephrol 2000; 11: 369-375. [Medline]

11. Kirsch BM, Sunder-Plassmann G, Schwarz C. Metabolic alkalosis in a hemodialysis patient--successful treatment with a proton pump inhibitor. Clin Nephrol 2006; 66: 391-394. [Medline] [CrossRef]

12. Wight CO, Seed M, Yeo WW, et al. Gastric outflow obstruction caused by gall stones and leading to death by complex metabolic derangement. J Clin Pathol 1997; 50: 963-965. [Medline] [CrossRef]

13. Akimoto T, Saito O, Kotoda A, et al. A case of recurrent renal failure associated with metabolic alkalosis induced by protracted vomiting. Clin Exp Nephrol 2006; 10: 279-283. [Medline] [CrossRef]

14. Siow SL, Wong CM, Sohail M. Adult pyloric stenosis masquerading as acute renal failure. Med J Malaysia 2009; 64: 168-169. [Medline] 